\title{
Estrutura do componente arbóreo e características edáficas de dois fragmentos de floresta estacional decidual no vale do rio Araguari, MG, Brasil
}

\author{
Ariane de Souza Siqueira ${ }^{1,3}$, Glein Monteiro de Araújo ${ }^{2}$ Ivan Schiavini²
}

Recebido em 22/06/2007. Aceito em 14/03/2008

\begin{abstract}
RESUMO - (Estrutura do componente arbóreo e características edáficas de dois fragmentos de floresta estacional decidual no vale do rio Araguari, MG, Brasil). Este trabalho investigou a estrutura do componente arbóreo e as características edáficas de duas florestas deciduais (doravante Funil 1 e Funil 2) localizadas no vale do rio Araguari, Triângulo Mineiro. Foram demarcadas 60 parcelas de 10×20 m em cada área. Todas as árvores com circunferência a $1,30 \mathrm{~m}$ de altura $\geq 15 \mathrm{~cm}$ foram amostradas. Para o estudo do solo foram realizadas análises físicas e químicas de 20 amostras de cada ambiente. Para verificar possíveis relações entre as características do solo e a distribuição das espécies foram realizadas análises de correspondência canônica (CCA). Funil 1 apresentou densidade de 1695 ind./ha e área basal total de 16,25 m²/ha. Foram amostradas 64 espécies, 49 gêneros e 32 famílias nesse ambiente. Funil 2 apresentou densidade de 937,5 ind./ha, área basal total de 14,02 $\mathrm{m}^{2} /$ ha e total de 46 espécies, 39 gêneros e 22 famílias. O índice de diversidade de Shannon foi de 2,76 (Funil 1) e 2,59 (Funil 2), sendo a equabilidade semelhante para os dois ambientes (J'=0,66). As análises químicas evidenciaram fortes semelhanças entre os solos estudados. Em contraste, houve diferença considerável dos parâmetros físicos desses solos. A umidade dos solos de Funil 1 e 2 variou ao longo do ano (ANOVA $F=367,67 ; g l=3 ; p<0,001$ ), sendo o mês de dezembro o mais úmido e o mês de setembro o mais seco. A CCA realizada para as duas florestas sugere que a maioria das espécies distribui-se por toda área, alterando apenas suas abundâncias relativas.
\end{abstract}

Palavras-chave: distribuição de espécies, fitossociologia, floresta estacional decidual, solos

\begin{abstract}
Tree layer structure and soil characteristics of two deciduous dry forests in the Araguari river valley, Minas Gerais State, Brazil). This study aimed to analyze the vegetation structure and soil characteristics of two deciduous forests, hereafter referred to as Funil 1 and Funil 2, located in the Araguari river valley, Triângulo Mineiro region. Sixty 10×20 m plots were laid out in each forest. All trees with a minimum circumference of $15 \mathrm{~cm}$ at $1.30 \mathrm{~m}$ above ground were sampled. Soil samples were collected from 20 plots in each forest. Canonical correspondence analysis (CCA) was used to check relationships between species distribution and soil characteristics. Funil 1 had a density of $1695 \mathrm{ind}$./ha and basal area of $16.25 \mathrm{~m}^{2} / \mathrm{ha}$. A total of 64 species, 49 genera and 32 families were found in the area. Funil 2 had a density of $937.5 \mathrm{ind}$./ha, basal area of $14.02 \mathrm{~m}^{2} /$ ha and a total of 46 species, 39 genera and 22 families. Shannon's index for Funil 1 and Funil 2 was 2.76 and 2.59, respectively. Pielou's evenness index was the same in both environments $(\mathrm{J}$ ' $=0.66)$. Chemical analysis of forest soils showed high similarity. In contrast, there were significant physical differences between Funil 1 and Funil 2 soils. Soil humidity of Funil 1 and 2 changed during the year (ANOVA $F=367.67 ; d f=3 ; p<0.001$ ); December was the wettest month and September, the driest month. Canonical correspondence analysis showed that most of the species were distributed throughout the area in both forests, differing only abundance.
\end{abstract}

Key words: deciduous dry forest, phytosociology, soils, species distribution

\section{Introdução}

A vida se constrói sobre as propriedades físicas e as reações químicas da matéria, e se manifesta sob diferentes aspectos em virtude das relações que estabelece com o ambiente físico (Ricklefs 2003). Nesse sentido, umas das principais questões inerentes ao estudo de comunidades vegetais é a determinação dos fatores responsáveis pela sua estrutura e distribuição. As florestas estacionais deciduais, fitofisionomias caracterizadas por acentuada estacionalidade climática e pela caducifolia pronunciada do estrato dominante (Veloso et al. 1991), sofrem, assim como outros ambientes, variações em sua estrutura e composição de espécies em decorrência de fatores abióticos. Os níveis de caducifolia dessas formações, por exemplo, podem variar de fragmento para fragmento em decorrência de características físicas, químicas e, principalmente, da

\footnotetext{
1 Universidade Federal de Uberlândia, Programa de Pós-graduação em Ecologia e Conservação de Recursos Naturais, Campus Umuarama, Rua Ceará s.n., Bloco 2D, 38400-902 Uberlândia, MG, Brasil

2 Universidade Federal de Uberlândia, Instituto de Biologia, Campus Umuarama, Rua Ceará s.n., 38400-902 Uberlândia, MG, Brasil

3 Autor para correspondência: arianebio@yahoo.com.br
} 
profundidade do solo (Nascimento et al. 2004). Diferenças no volume de precipitação e na duração da estação chuvosa também são responsáveis por variações entre esses fragmentos (Mooney et al. 1995).

As florestas estacionais deciduais estão distribuídas pelas mais diversas regiões tropicais do planeta, sob a forma de um continuum florestal ou de fragmentos naturais isolados por outros tipos de vegetação (Scariot \& Sevilha 2005). Essa conformação fragmentada e, na maioria das vezes, disjunta, é considerada como um vestígio de uma distribuição contínua e muito mais ampla no passado, quando o clima mais frio e seco causou a retração das florestas úmidas para zonas fluviais e, consequentemente, as florestas estacionais predominaram (Prado \& Gibbs 1993). No Brasil, essas florestas distribuem-se tanto pelas formações savânicas de Cerrado e Caatinga, nas regiões Centro-Oeste e Nordeste, quanto pelas formações florestais sempre-verdes da floresta Amazônica e Atlântica, nas regiões Norte e Sul/Sudeste respectivamente (Scariot \& Sevilha 2005). No Triângulo Mineiro, as florestas estacionais deciduais são encontradas sobre diferentes tipos de solos, derivados do basalto e de outras rochas, em encostas voltadas para cursos fluviais (Baruqui \& Motta 1983; Araújo et al. 1997; Souza et al. 2006).

Estudos ecológicos direcionados às florestas estacionais deciduais investigaram sua composição florística (Rodrigues \& Araújo 1997), estrutura fitossociológica (Araújo et al. 1997; Pedralli 1997) e relações entre a estrutura da floresta e as características do solo (Oliveira Filho et al. 1998; Souza et al. 2006). Porém, estes estudos ainda são poucos e a falta de informações que contemplem, principalmente, os aspectos edáficos dessa fitofisionomia tem dificultado eventuais comparações entre os diferentes fragmentos florestais (Scariot \& Sevilha 2005).

Este trabalho teve como objetivo determinar a estrutura do componente arbóreo e características do solo de dois fragmentos de floresta estacional decidual localizados no vale do rio Araguari, Triângulo Mineiro e, a partir dos dados obtidos, responder às seguintes questões: i) quais são as semelhanças estruturais entre os dois fragmentos de floresta estacional decidual estudados? ii) quais são as principais diferenças químicas e físicas dos solos entre os dois fragmentos florestais? iii) como se comporta a umidade do solo, ao longo do ano, nesses dois ambientes? iv) as propriedades químicas e físicas dos solos nesses ambientes interferem na distribuição das espécies arbóreas?

\section{Material e métodos}

Clima e solo da região - A região do Triângulo Mineiro, onde se encontra o vale do rio Araguari, apresenta acentuada sazonalidade climática, sendo possível distinguir duas estações bem definidas: uma seca, que compreende os meses de abril a setembro, e outra chuvosa, entre os meses de outubro e março (Rosa et al. 1991). Segundo dados disponíveis no sistema de informações meteorológicas do Estado de Minas Gerais (SIMGE 2006), a região do vale do rio Araguari apresentou, durante o ano de 2005, uma temperatura média de $25^{\circ} \mathrm{C}$, atingindo máximas de $31^{\circ} \mathrm{C}$ no verão e mínimas de $19^{\circ} \mathrm{C}$ no inverno. A precipitação durante o referido ano foi de $1.400 \mathrm{~mm}$, sendo registrados 120 dias de chuvas.

Os principais tipos de solos encontrados na região do vale do rio Araguari são do tipo Argissolo VermelhoAmarelo eutrófico e Cambissolo Háplico Tb eutrófico (EMBRAPA 1982). Afloramentos de basalto provenientes da formação Serra Geral e rochas de micaxisto e biotitagnaisse do grupo Araxá também compõem o cenário edáfico da região (Baruqui \& Motta 1983; Nishiyama 1989).

Localização e descrição geral da área de estudo - Os dois fragmentos de floresta decidual avaliados no presente trabalho, e aqui denominados Funil 1 e Funil 2, localizam-se no vale do rio Araguari, em áreas que, em um passado recente, sofreram impactos antrópicos: corte seletivo e queimadas. Atualmente, as áreas ocupadas por Funil 1 e 2 fazem parte da Área de Preservação Permanente da Usina Hidroelétrica (UHE) Amador Aguiar 1.

Funil 1 ( $18^{\circ} 47^{\prime} \mathrm{S}$ e $\left.48^{\circ} 06^{\prime} \mathrm{W}\right)$ é uma área de floresta secundária com, aproximadamente, 17 ha, apresentando em seu entorno um trecho de cerradão antropizado e áreas de pastagens e lavouras. Localiza-se na propriedade particular denominada Fazenda do Salto, município de Araguari (MG) a uma altitude aproximada de $625 \mathrm{~m}$. O solo em Funil 1 é raso e apresenta afloramentos de rochas do tipo biotita-xisto em diversos pontos do terreno. De acordo com Sistema de Classificação de Solos da EMBRAPA (1999) esse solo enquadra-se na classe Neossolo Litólico com substrato de biotita-xisto (G.F. Corrêa, comunicação pessoal).

Funil $2\left(18^{\circ} 48^{\prime} \mathrm{S}\right.$ e $\left.48^{\circ} 07^{\prime} \mathrm{W}\right)$ possui uma área de floresta secundária de, aproximadamente, 68 ha de extensão e apresenta em seu entorno pequenos fragmentos de floresta decidual secundária em meio a áreas de pastagens. Localiza-se na propriedade particular denominada Fazenda Tenda, município de Uberlândia (MG), a uma altitude aproximada de $625 \mathrm{~m}$. O solo de Funil 2 é raso, sendo comuns afloramentos de rocha em vários pontos da área. Segundo o Sistema de Classificação de Solos da EMBRAPA (1999) esse solo pertence à classe dos Neossolos Litólicos com substrato de rocha granítica (G.F. Corrêa, comunicação pessoal).

Fitossociologia - A avaliação fitossociológica dos dois 
fragmentos florestais foi realizada utilizando-se o método de parcelas (Mueller-Dombois \& Ellenberg 1974). Em cada área, foram demarcadas 60 parcelas de $10 \mathrm{~m} \times 20 \mathrm{~m}$, totalizando 1,2 ha de amostragem. As parcelas foram alocadas, em ambas as áreas, a partir da cota de $624 \mathrm{~m}$, que representa a linha de inundação da barragem de Amador Aguiar 1, dentro do limite de uma área de preservação permanente (Fig. 1). Todos os indivíduos vivos que apresentaram circunferência a altura do peito (CAP) $\geq 15 \mathrm{~cm}$ foram amostrados, sendo determinadas sua espécie, altura e CAP. Para cada espécie foram calculados os parâmetros fitossociológicos descritos por Mueller-Dombois \& Ellenberg (1974). A determinação da diversidade de espécies nas duas florestas foi realizada por meio do cálculo dos índices de diversidade de Shannon (H') e de equabilidade de Pielou (J'). Para a obtenção de todos esses parâmetros foi utilizado o programa FITOPAC I (Shepherd 1995).

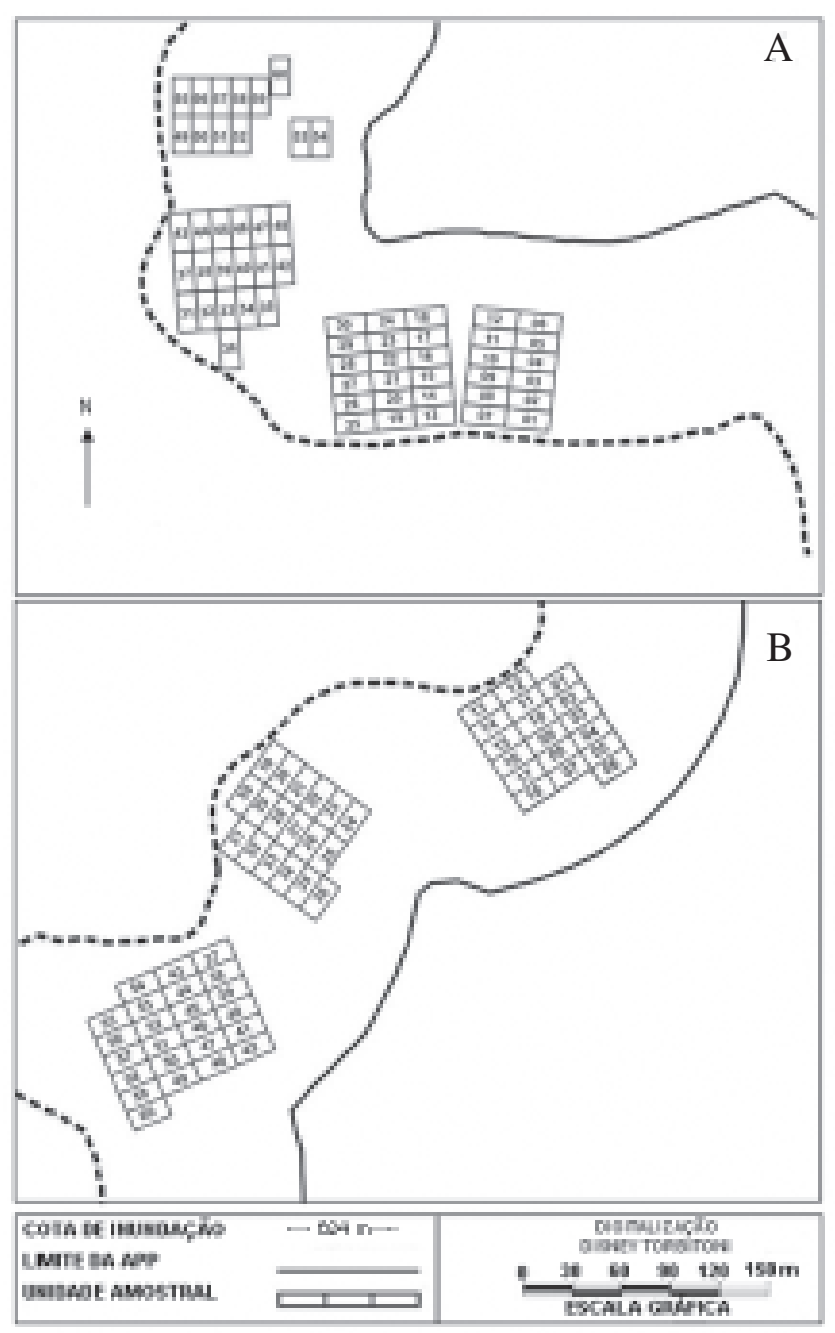

Figura 1. Disposição das unidades amostrais empregadas no levantamento fitossociológico realizado em Funil 1 (A) e Funil 2 (B), vale do rio Araguari, MG, Brasil.
A avaliação quantitativa da similaridade da flora presente nos dois fragmentos estudados foi realizada mediante cálculo do índice de Morisita (Felfili et al. 1993). Foi adotado o sistema APGII para a classificação das famílias (Souza \& Lorenzi 2005). Para cada área estudada foram preparadas distribuições de densidade de árvores por classes de diâmetro e de altura. Conforme recomendações de Oliveira Filho et al. (2001), no caso dos diâmetros, foram empregados intervalos de classe com amplitudes crescentes para compensar o forte decréscimo da densidade nas maiores classes de tamanho, típico da distribuição em J-invertido.

Coleta e análises físicas e químicas - Para a avaliação das características físicas e químicas do solo foram coletadas amostras de 20 parcelas selecionadas aleatoriamente em cada área, obedecendo-se ao seguinte critério: dez parcelas localizadas na porção inferior, próximo à cota de $624 \mathrm{~m}$, e as outras dez parcelas localizadas na porção superior, a aproximadamente $50 \mathrm{~m}$ das primeiras. Em cada parcela foram retiradas três amostras (canto superior, centro e canto inferior) a uma profundidade de $0-20 \mathrm{~cm}$, formando-se uma única amostra composta por parcela.

As análises químicas foram realizadas no Laboratório de Solos do Departamento de Ecologia da Universidade de Brasília, onde foram determinados os seguintes parâmetros: $\mathrm{pH}, \mathrm{P}, \mathrm{K}, \mathrm{Ca}, \mathrm{Mg}, \mathrm{Al}, \mathrm{Fe}, \mathrm{Mn}, \mathrm{C}$ e N. O pH foi medido em solução de $\mathrm{H}_{2} \mathrm{O}$ e $\mathrm{KCl} 1 \mathrm{M}$. Para a extração de $\mathrm{Ca}^{2+}, \mathrm{Mg}^{2+}$ e $\mathrm{Al}^{3+}$ trocáveis foi utilizado o extrato de $\mathrm{KCl} 1 \mathrm{M}$. Para os demais nutrientes $\left(\mathrm{P}, \mathrm{K}^{1+}\right.$, $\mathrm{Fe}^{3+}$ e $\mathrm{Mn}^{2+}$ ) foi utilizado o extrato de Mellich $\left(\mathrm{H}_{2} \mathrm{SO}_{4^{-}}\right.$0,0125 M + $\mathrm{HCl} 0,05 \mathrm{M}$ ) (Allen 1974). O Al foi obtido por titulação com $\mathrm{NaOH}(0,025 \mathrm{M})$. O teor de $\mathrm{P}$ foi obtido por colorimetria, utilizando-se o molibdato de amônia a um comprimento de onda de $660 \mathrm{~nm}$. O teor de $\mathrm{C}$ foi determinado por titulação e o de $\mathrm{N}$ foi obtido pelo método de Kieldahl (Allen 1974).

As análises de textura foram realizadas no Laboratório de Manejo de Solos (LAMAS) da Universidade Federal de Uberlândia, segundo procedimentos adotados pela EMBRAPA (1997). Por meio dessas análises foi verificado a fração granulométrica de areia grossa e areia fina, silte e argila (em g.kg-1) presente nos solos estudados.

Umidade à base de massa - Para verificar a variação da umidade do solo ao longo do ano foram realizadas coletas nos meses de março, junho, setembro e dezembro nos dois ambientes estudados. Em cada área, foram escolhidos dez pontos, sendo cinco próximos a cota de $624 \mathrm{~m}$ do conjunto de parcelas, e os outros cinco distantes $15 \mathrm{~m}$ dos primeiros. Em cada ponto foram coletadas amostras de solo nas profundidades de 0-10 cm, 20-30 cm e de 40-50 cm. A determinação do 
teor de umidade presente nos solos amostrados foi realizada mediante metodologia empregada pela EMBRAPA (1997).

Variação da umidade do solo - Para verificar a variação da umidade do solo ao longo do ano e ao longo das três diferentes profundidades, descritas anteriormente, foi realizada uma análise de variância (ANOVA) em blocos casualizados para cada área. Para a realização dessas análises foi utilizado o programa Systat 10.2.

Distribuição das espécies versus características edáficas - Para verificar se as propriedades físicas e químicas dos solos estudados influenciam a distribuição das espécies arbóreas foi realizada, segundo recomendações de Ter Braak (1987), uma análise de correspondência canônica (Cannonical Correspondence Analysis - CCA). Para a construção da matriz de abundância das espécies foram utilizadas as mesmas 20 parcelas onde foi feita a coleta do solo para análises físicas e químicas. A partir dos dados de abundância das espécies obtidos para as referidas parcelas, foram selecionadas aquelas espécies que contribuíram com 5\% ou mais para o total de indivíduos da amostra. A razão básica para a adoção desse procedimento é que as espécies raras ou com baixa densidade tem pouco ou nenhuma influência nos resultados de ordenações e sua eliminação reduz o montante de cálculos (Causton 1988). A significância da correlação entre as variáveis ambientais foi avaliada pelo teste de permutação de Monte Carlo. A matriz de variáveis ambientais incluiu, a princípio, todos os parâmetros químicos e texturais do solo. Após a realização de uma CCA preliminar todas as variáveis fracamente correlacionadas com a distribuição das espécies $(\mathrm{p}<0,05)$ foram eliminadas. Para a realização dessas análises foi utilizado o programa Canoco (Ter Braak 1988).

\section{Resultados}

Estrutura da comunidade arbórea - Funil 1 apresentou densidade de 1695 ind./ha e área basal total de $16,25 \mathrm{~m}^{2} / \mathrm{ha}$. Sessenta e quatro espécies distribuídas em 49 gêneros e 32 famílias foram amostradas nesse ambiente (Tab. 1). A comunidade vegetal de Funil 2 apresentou densidade de 937,5 ind./ha e área basal total de 14,02 $\mathrm{m}^{2} / \mathrm{ha}$. Quarenta e seis espécies pertencentes a 39 gêneros e 22 famílias foram amostradas nesse ambiente (Tab. 1). O índice de diversidade de Shannon obtido para Funil 1 e Funil 2 foi de 2,76 e 2,59, respectivamente, sendo a equabilidade semelhante para os dois ambientes $\left(\mathrm{J}^{\prime}=0,66\right)$. As quatro espécies de maior ocorrência em Funil 1 concentraram 54,92\% dos indivíduos. Por outro lado, 16 espécies foram representadas por apenas um indivíduo (Tab. 1). Em Funil 2, as quatro espécies mais abundantes concentraram $63 \%$ do total de indivíduos, e 11 espécies foram representadas por apenas um indivíduo (Tab. 1). $\mathrm{O}$ valor da similaridade, em termos de abundância de espécies, calculada para as áreas estudadas por meio do índice de Morisita foi de 0,53.

As florestas estacionais deciduais de Funil 1 e 2 são caracterizadas por grande ocorrência de indivíduos da espécie Myracrodruon urundeuva (aroeira), tendo a mesma o maior VI nas duas comunidades vegetais (Tab. 1). Myrsine umbellata, Myrcia splendens e Campomanesia velutina estão entre as espécies de maior VI em Funil 1, enquanto em Funil 2 Tabebuia roseoalba, Anadenanthera colubrina e Campomanesia velutina encontram-se entre as de maior VI (Tab. 1).

Segundo resultados do teste de KolgomorovSminorv, as distribuições de densidade de árvores por classes de diâmetro $(\mathrm{p}=0,116 ; \mathrm{p}<0,05)$ e altura $(\mathrm{p}=0,148 ; \mathrm{p}<0,05)$ entre os ambientes estudados não apresentaram diferenças significativas. A comunidade arbórea de Funil 1 é formada, predominantemente, por indivíduos de alturas entre 5 e 10 metros (Fig. 2A). Destacam-se nesse estrato, em virtude do grande número de indivíduos, as mesmas espécies que apareceram com os maiores valores de importância dessa
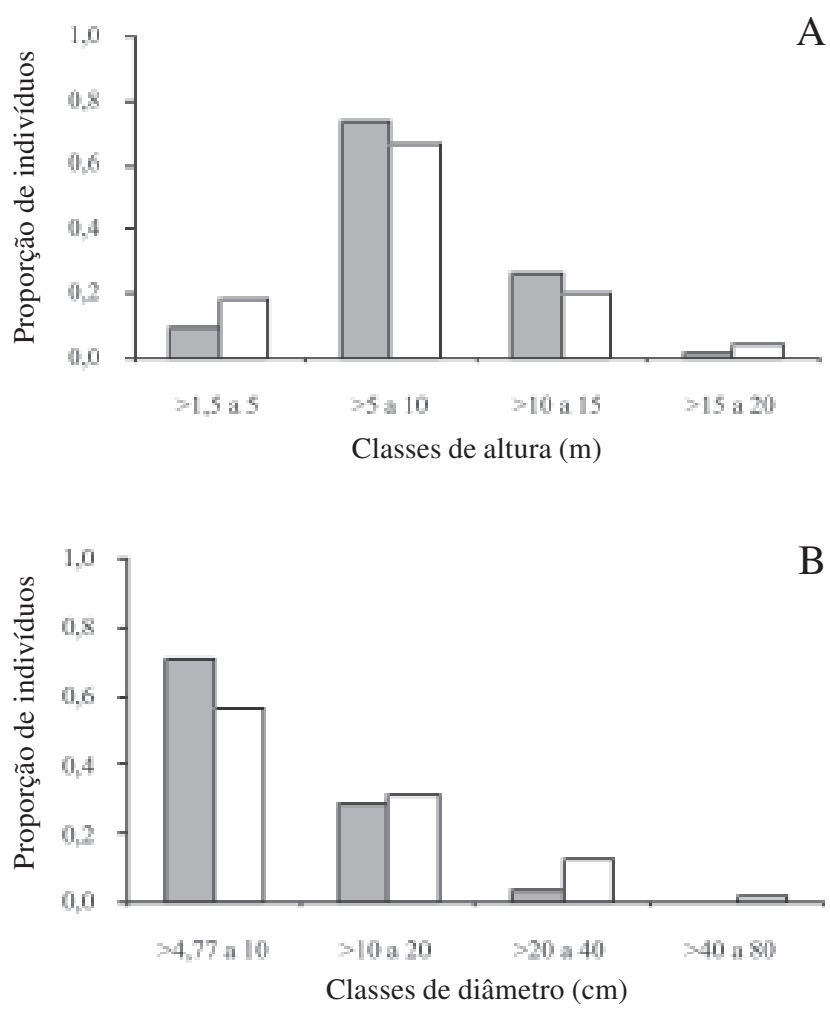

Figura 2. Proporção de indivíduos arbóreos observados em diferentes classes de altura (A) e diâmetro (B) nas florestas deciduais de Funil 1 $(\square)$ e Funil 2 ( $\square$ ), vale do rio Araguari, MG, Brasil. 
14 Siqueira, Araújo \& Schiavini: Estrutura do componente arbóreo e características edáficas de dois fragmentos...

Tabela 1. Espécies arbóreas, em ordem de valor de importância (VI) de Funil 1, amostradas em dois fragmentos de florestas deciduais (Funil 1 e Funil 2) no vale do rio Araguari, MG, Brasil. $\mathrm{NI}=$ número de indivíduos; $\mathrm{DR}=$ densidade relativa; $\mathrm{FR}=$ freqüência relativa; DoR = dominância relativa.

\begin{tabular}{|c|c|c|c|c|c|c|c|c|c|c|}
\hline \multirow[t]{2}{*}{ Espécies/Famílias } & \multicolumn{5}{|c|}{ Funil 1} & \multicolumn{5}{|c|}{ Funil 2} \\
\hline & NI & DR & FR & DoR & VI & NI & DR & FR & DoR & VI \\
\hline Myracrodruon urundeuva Allemão [Anacardiaceae] & 412 & 18,09 & 24,43 & 8,17 & 50,69 & 281 & 23,42 & 29,56 & 12,45 & 65,42 \\
\hline Myrsine umbellata Mart. [Myrsinaceae] & 264 & 11,59 & 12,59 & 5,99 & 30,17 & 15 & 1,25 & 0,57 & 1,69 & 3,51 \\
\hline Myrcia splendens (Sw.) DC. [Myrtaceae] & 272 & 11,94 & 9,38 & 7,77 & 29,09 & 1 & 0,08 & 0,01 & 0,21 & 0,30 \\
\hline $\begin{array}{l}\text { Campomanesia velutina (Cambess.) O. Berg. } \\
\text { [Myrtaceae] }\end{array}$ & 303 & 13,3 & 8,21 & 6,01 & 28,05 & 93 & 7,75 & 6,98 & 6,75 & 21,48 \\
\hline Morta & 244 & 10,31 & 7,05 & 6,82 & 24,18 & 75 & 6,25 & 4,81 & 8,23 & 19,30 \\
\hline Lithraea molleoides (Vell.) Engl. [Anacardiaceae] & 130 & 5,71 & 6,54 & 6,27 & 18,51 & 0 & 0 & 0 & 0 & 0 \\
\hline Anadenanthera colubrina (Vell.) Brenan [Fabaceae] & 115 & 5,05 & 6,55 & 6,54 & 18,13 & 138 & 11,50 & 18,48 & 9,07 & 39,01 \\
\hline Cecropia pachystachya Trècul [Urticaceae] & 58 & 2,55 & 3,22 & 3,81 & 9,58 & 6 & 0,50 & 0,63 & 1,27 & 2,40 \\
\hline Tabebuia roseo-alba (Ridley) Sandw. [Bignoniaceae] & 58 & 2,55 & 2,77 & 4,22 & 9,54 & 245 & 20,42 & 16,19 & 11,39 & 47,99 \\
\hline Guazuma ulmifolia Lam. [Malvaceae] & 49 & 2,15 & 1,91 & 3,68 & 7,74 & 19 & 1,58 & 0,97 & 2,74 & 5,30 \\
\hline Rhamnidium elaeocarpum Reissek [Rhamnaceae] & 45 & 1,98 & 1,63 & 4,09 & 7,69 & 10 & 0,83 & 0,20 & 1,90 & 2,93 \\
\hline Dilodendron bipinnatum Radlk. [Sapindaceae] & 29 & 1,27 & 1,91 & 3,00 & 6,18 & 4 & 0,33 & 0,06 & 0,84 & 1,24 \\
\hline Tapirira guianensis Aubl. [Anacardiaceae] & 30 & 1,32 & 1,61 & 2,18 & 5,11 & 1 & 0,08 & 0,02 & 0,21 & 0,31 \\
\hline Cordia alliodora Cham. [Boraginaceae] & 22 & 0,97 & 0,98 & 2,45 & 4,40 & 7 & 0,58 & 0,42 & 1,48 & 2,48 \\
\hline Terminalia phaeocarpa Eichl. [Combretaceae] & 20 & 0,88 & 0,84 & 2,45 & 4,17 & 0 & 0 & 0 & 0 & 0 \\
\hline Matayba guianensis Aubl. [Sapindaceae] & 23 & 1,01 & 0,49 & 2,59 & 4,08 & 9 & 0,75 & 0,31 & 1,48 & 2,53 \\
\hline Terminalia glabrescens Mart. [Combretaceae] & 11 & 0,48 & 1,88 & 1,50 & 3,86 & 0 & 0 & 0 & 0 & 0 \\
\hline Inga vera Willd. [Fabaceae] & 16 & 0,70 & 0,87 & 1,23 & 2,80 & 0 & 0 & 0 & 0 & 0 \\
\hline Casearia mariquitensis Kunth [Salicaceae] & 18 & 0,79 & 0,47 & 1,50 & 2,76 & 24 & 2 & 1,02 & 3,80 & 6,82 \\
\hline Byrsonima sp.2 [Malpighiaceae] & 14 & 0,61 & 0,45 & 1,63 & 2,70 & 0 & 0 & 0 & 0 & 0 \\
\hline Casearia sylvestris $\mathrm{Sw}$. [Salicaceae] & 10 & 0,44 & 0,15 & 1,36 & 1,95 & 9 & 0,75 & 0,15 & 1,90 & 2,80 \\
\hline Machaerium hirtum (Vell.) Stellfeld [Fabaceae] & 11 & 0,48 & 0,59 & 0,68 & 1,76 & 5 & 0,42 & 1,05 & 1,05 & 2,52 \\
\hline Piptadenia gonoacantha (Mart.) J.F. Macbr. [Fabaceae] & 6 & 0,26 & 0,44 & 0,82 & 1,52 & 70 & 5,83 & 4,49 & 6,54 & 16,86 \\
\hline Eugenia florida DC. [Myrtaceae] & 7 & 0,31 & 0,16 & 0,95 & 1,42 & 0 & 0 & 0 & 0 & 0 \\
\hline Eugenia pluriflora DC. [Myrtaceae] & 7 & 0,31 & 0,15 & 0,95 & 1,41 & 0 & 0 & 0 & 0 & 0 \\
\hline $\begin{array}{l}\text { Chrysophyllum marginatum (Hook. \& Arn.) Radlk. } \\
\text { [Sapotaceae] }\end{array}$ & 5 & 0,22 & 0,37 & 0,68 & 1,27 & 0 & 0 & 0 & 0 & 0 \\
\hline Astronium fraxinifolium Schott [Anacardiaceae] & 5 & 0,22 & 0,30 & 0,68 & 1,20 & 5 & 0,42 & 0,37 & 1,05 & 1,84 \\
\hline Cupania vernalis Cambess. [Sapindaceae] & 5 & 0,22 & 0,30 & 0,68 & 1,20 & 1 & 0,08 & 0,06 & 0,21 & 0,36 \\
\hline Machaerium brasiliense Vogel [Fabaceae] & 6 & 0,26 & 0,11 & 0,68 & 1,06 & 6 & 0,50 & 0,24 & 1,05 & 1,80 \\
\hline Xylopia aromatica Lam. [Annonaceae] & 6 & 0,26 & 0,10 & 0,68 & 1,05 & 0 & 0 & 0 & 0 & 0 \\
\hline Luehea divaricata Mart. [Malvaceae] & 6 & 0,26 & 0,21 & 0,54 & 1,02 & 0 & 0 & 0 & 0 & 0 \\
\hline Coccoloba mollis Casar [Polygonaceae] & 4 & 0,18 & 0,26 & 0,54 & 0,98 & 0 & 0 & 0 & 0 & 0 \\
\hline Pouteria torta (Mart.) Radlk. [Sapotaceae] & 6 & 0,26 & 0,25 & 0,41 & 0,93 & 0 & 0 & 0 & 0 & 0 \\
\hline Inga laurina (Sw.) Willd. [Fabaceae] & 4 & 0,18 & 0,18 & 0,54 & 0,90 & 0 & 0 & 0 & 0 & 0 \\
\hline Protium heptaphyllum March. [Burseraceae] & 4 & 0,18 & 0,09 & 0,54 & 0,81 & 0 & 0 & 0 & 0 & 0 \\
\hline Bauhinia ungulata L. [Fabaceae] & 4 & 0,18 & 0,05 & 0,54 & 0,77 & 28 & 2,33 & 0,49 & 1,27 & 4,09 \\
\hline Myrcia tomentosa (Aubl.) DC. [Myrtaceae] & 4 & 0,18 & 0,12 & 0,41 & 0,71 & 0 & 0 & 0 & 0 & 0 \\
\hline Byrsonima laxiflora Griseb. [Malpighiaceae] & 4 & 0,18 & 0,08 & 0,41 & 0,67 & 0 & 0 & 0 & 0 & 0 \\
\hline Apeiba tibourbou Aubl. [Malvaceae] & 3 & 0,13 & 0,11 & 0,41 & 0,65 & 4 & 0,33 & 0,08 & 0,84 & 1,25 \\
\hline Casearia gossypiosperma Brinq. [Salicaceae] & 3 & 0,13 & 0,07 & 0,41 & 0,61 & 9 & 0,75 & 0,28 & 1,69 & 2,72 \\
\hline Ocotea minarum (Nees \& C. Mart.) Mez [Lauraceae] & 1 & 0,04 & 0,38 & 0,14 & 0,56 & 0 & 0 & 0 & 0 & 0 \\
\hline Byrsonima pachyphylla Nied. [Malpighiaceae] & 3 & 0,13 & 0,04 & 0,27 & 0,44 & 0 & 0 & 0 & 0 & 0 \\
\hline Psidium sp. [Myrtaceae] & 3 & 0,13 & 0,04 & 0,27 & 0,44 & 0 & 0 & 0 & 0 & 0 \\
\hline Styrax camporum Pohl [Styracaceae] & 2 & 0,09 & 0,08 & 0,27 & 0,44 & 0 & 0 & 0 & 0 & 0 \\
\hline $\begin{array}{l}\text { Handroanthus chrysotrichus (Mart. ex A. DC.) Mattos } \\
\text { [Bignoniaceae] }\end{array}$ & 2 & 0,09 & 0,06 & 0,27 & 0,42 & 4 & 0,33 & 0,09 & 0,84 & 1,26 \\
\hline Andira anthelmia (Vell.) Macbr. [Fabaceae] & 2 & 0,09 & 0,04 & 0,27 & 0,40 & 0 & 0 & 0 & 0 & 0 \\
\hline Trichilia catigua A. Juss. [Meliaceae] & 2 & 0,09 & 0,04 & 0,27 & 0,40 & 0 & 0 & 0 & 0 & 0 \\
\hline Pouteria gardneri (Mart. \& Miq.) Baehni [Sapotaceae] & 2 & 0,09 & 0,03 & 0,27 & 0,39 & 1 & 0,08 & 0,01 & 0,21 & 0,31 \\
\hline Acacia polyphylla DC. [Fabaceae] & 2 & 0,09 & 0,08 & 0,14 & 0,30 & 41 & 3,42 & 1,50 & 5,91 & 10,83 \\
\hline Diospyros hispida A. DC. [Ebenaceae] & 1 & 0,04 & 0,11 & 0,14 & 0,29 & 0 & 0 & 0 & 0 & 0 \\
\hline Albizia sp. [Fabaceae] & 1 & 0,04 & 0,10 & 0,14 & 0,28 & 0 & 0 & 0 & 0 & 0 \\
\hline Aspidosperma subincanum Mart. [Apocynaceae] & 1 & 0,04 & 0,10 & 0,14 & 0,28 & 0 & 0 & 0 & 0 & 0 \\
\hline Acrocomia aculeata (Jacq.) Lodd. ex Mart. [Arecaceae] & 1 & 0,04 & 0,08 & 0,14 & 0,26 & 11 & 0,92 & 3,42 & 1,27 & 5,60 \\
\hline Curatella americana $\mathrm{L}$. [Dilleniaceae] & 1 & 0,04 & 0,05 & 0,14 & 0,23 & 0 & 0 & 0 & 0 & 0 \\
\hline
\end{tabular}


Tabela 1 (continuação)

\begin{tabular}{|c|c|c|c|c|c|c|c|c|c|c|}
\hline \multirow[t]{2}{*}{ Espécies/Famílias } & \multicolumn{5}{|c|}{ Funil 1} & \multicolumn{5}{|c|}{ Funil 2} \\
\hline & $\mathrm{NI}$ & DR & FR & DoR & VI & NI & $\mathrm{DR}$ & FR & DoR & VI \\
\hline $\begin{array}{l}\text { Lonchocarpus cultratus (Vell.) A.M.G. Azevedo \& } \\
\text { H.C. Lima [Fabaceae] }\end{array}$ & 1 & 0,04 & 0,04 & 0,14 & 0,22 & 4 & 0,33 & 0,32 & 0,84 & 1,50 \\
\hline Qualea multiflora Mart. [Vochysiaceae] & 1 & 0,04 & 0,03 & 0,14 & 0,21 & 0 & 0 & 0 & 0 & 0 \\
\hline Hymenaea courbaril L. [Fabaceae] & 1 & 0,04 & 0,02 & 0,14 & 0,20 & 1 & 0,08 & 0,24 & 0,21 & 0,54 \\
\hline Qualea grandiflora Mart. [Vochysiaceae] & 1 & 0,04 & 0,02 & 0,14 & 0,20 & 0 & 0 & 0 & 0 & 0 \\
\hline Erythroxylum daphnites Mart. [Erythroxylaceae] & 1 & 0,04 & 0,01 & 0,14 & 0,19 & 0 & 0 & 0 & 0 & 0 \\
\hline Maytenus floribunda Reissek [Celastraceae] & 1 & 0,04 & 0,01 & 0,14 & 0,19 & 0 & 0 & 0 & 0 & 0 \\
\hline Qualea dichotoma (Mart.) Warm. [Vochysiaceae] & 1 & 0,04 & 0,01 & 0,14 & 0,19 & 0 & 0 & 0 & 0 & 0 \\
\hline Salacia elliptica (Mart. ex Schult.) G. Don [Celastraceae] & 1 & 0,04 & 0,01 & 0,14 & 0,19 & 0 & 0 & 0 & 0 & 0 \\
\hline $\begin{array}{l}\text { Handroanthus serratifolius (Vahl) S.O. Grose } \\
\text { [Bignoniaceae] }\end{array}$ & 1 & 0,04 & 0,01 & 0,14 & 0,19 & 0 & 0 & 0 & 0 & 0 \\
\hline Platypodium elegans Vogel [Fabaceae] & 1 & 0,04 & 0,01 & 0,14 & 0,19 & 21 & 1,75 & 3,27 & 2,11 & 7,13 \\
\hline Zanthoxyllum rhoifolium Lam. [Rutaceae] & 1 & 0,04 & 0,01 & 0,14 & 0,19 & 3 & 0,25 & 0,06 & 0,63 & 0,94 \\
\hline Aegiphyla sellowiana Cham. [Lamiaceae] & 0 & 0 & 0 & 0 & 0 & 2 & 0,17 & 0,11 & 0,42 & 0,70 \\
\hline Allophylus racemosus $\mathrm{Sw}$. [Sapindaceae] & 0 & 0 & 0 & 0 & 0 & 5 & 0,42 & 0,24 & 1,05 & 1,71 \\
\hline Aloysia virgata (Ruiz \& Pav.) Juss. [Verbenaceae] & 0 & 0 & 0 & 0 & 0 & 3 & 0,25 & 0,09 & 0,42 & 0,76 \\
\hline Aspidosperma olivaceum Muell. Arg. [Apocynaceae] & 0 & 0 & 0 & 0 & 0 & 3 & 0,17 & 0,05 & 0,42 & 0,64 \\
\hline Attalea phalerata Mart. ex Spreng. [Arecaceae] & 0 & 0 & 0 & 0 & 0 & 1 & 0,08 & 0,88 & 0,21 & 1,17 \\
\hline Celtis iguanea (Jacq.) Sargent [Cannabaceae] & 0 & 0 & 0 & 0 & 0 & 10 & 0,83 & 0,30 & 1,69 & 2,82 \\
\hline Chomelia pohliana Muell. Arg. [Rubiaceae] & 0 & 0 & 0 & 0 & 0 & 10 & 0,83 & 0,21 & 1,48 & 2,52 \\
\hline Chomelia sessilis Muell. Arg. [Rubiaceae] & 0 & 0 & 0 & 0 & 0 & 1 & 0,08 & 0,01 & 0,21 & 0,31 \\
\hline $\begin{array}{l}\text { Chrysophyllum gonocarpum (Mart. \& Eichl.) Engl. } \\
\text { [Sapotaceae] }\end{array}$ & 0 & 0 & 0 & 0 & 0 & 1 & 0,08 & 0,04 & 0,21 & 0,33 \\
\hline Enterolobium contortisiliquum (Vell.) Morong [Fabaceae] & 0 & 0 & 0 & 0 & 0 & 3 & 0,25 & 0,67 & 0,63 & 1,56 \\
\hline Eugenia sp. [Myrtaceae] & 0 & 0 & 0 & 0 & 0 & 1 & 0,08 & 0,02 & 0,21 & 0,31 \\
\hline Ficus sp. & 0 & 0 & 0 & 0 & 0 & 1 & 0,08 & 0,09 & 0,21 & 0,39 \\
\hline Maclura tinctoria (L.) D. Don ex Steud [Moraceae] & 0 & 0 & 0 & 0 & 0 & 7 & 0,58 & 0,20 & 1,27 & 2,05 \\
\hline Sterculia striata A. St.-Hil. \& Naudin [Malvaceae] & 0 & 0 & 0 & 0 & 0 & 1 & 0,08 & 0,74 & 0,21 & 1,03 \\
\hline $\begin{array}{l}\text { Tocoyena formosa (Cham. \& Schltdl.) K. Schum. } \\
\text { [Rubiaceae] }\end{array}$ & 0 & 0 & 0 & 0 & 0 & 1 & 0,08 & 0,01 & 0,21 & 0,31 \\
\hline
\end{tabular}

comunidade, somando-se a elas, Myrcia splendens e Lithraea molleoides. Com relação à classe $>15$ a 20 m de altura, foi inexpressivo o número de árvores presentes nesse estrato (Fig. 2A). Estão entre as árvores mais altas de Funil 1 as espécies Anadenanthera colubrina, Myracrodruon urundeuva e Myrsine umbellata. Em Funil 2 também houve maior concentração de indivíduos na classe de altura $>5$ a $10 \mathrm{~m}$ (Fig. 2A), sendo mais freqüentes nesse estrato, Piptadenia gonoacantha, Bauhinia ungulata e as quatro espécies de maior VI dessa comunidade (Tab. 1). A ocorrência de indivíduos de maior porte em Funil 2 também foi pequena (Fig. 2A), com destaque, mais uma vez, para Myracrodruon urundeuva e Anadenanthera colubrina. Com relação à distribuição dos indivíduos nas diferentes classes de diâmetros é possível observar que, tanto para Funil 1 quanto para Funil 2, houve maior concentração de árvores na classe $>4,77$ a $10 \mathrm{~cm}$, indicando acentuada presença de elementos arbóreos de diâmetro reduzido nesses ambientes (Fig. 2B).

Características químicas e físicas dos solos - As análises químicas realizadas nos solos de Funil 1 e 2 evidenciaram fortes semelhanças químicas entre os mesmos (Tab. 2). Os valores médios de $\mathrm{pH}$ obtido nos solos das duas florestas foram muito similares, não sendo detectada nenhuma diferença significativa entre esses valores (Tab. 2). A disponibilidade de nutrientes no solo também foi muito semelhante entre esses ambientes e, excetuando-se o K, suas concentrações não divergiram entre as duas áreas estudadas (Tab. 2). Em contraste à semelhança química constatada para os solos de Funil 1 e 2, foi observada uma diferença considerável dos parâmetros físicos apresentados por esses solos. O teor de cada uma das frações granulométricas do solo, com exceção para da argila, divergiu, significativamente, entre os dois ambientes (Tab. 2). O teor de areia grossa foi consideravelmente maior em Funil 2. Em contrapartida, a disponibilidade de areia fina, argila e silte foi, em média, superior em Funil 1 (Tab. 2).

Umidade à base de massa - A umidade dos solos de Funil 1 e 2, ao longo dos diferentes meses do ano, variou significativamente (ANOVA $F=367,67 ; g l=3$; $p<0,001)$, sendo o mês de dezembro o mais úmido e o mês de setembro o mais seco, em ambas as áreas 
Tabela 2. Características químicas e texturais de 20 amostras de Neossolo Litólico coletadas em 20 parcelas do levantamento fitossociológico realizado nas florestas deciduais de Funil 1 e 2, vale do rio Araguari, MG, Brasil. U = resultado do teste estatístico de Mann-Whitney; $\mathrm{p}=$ probabilidade da hipótese nula.

\begin{tabular}{|c|c|c|c|c|}
\hline Variáveis edáficas & $\begin{array}{c}\text { Funil } 1 \\
\text { Biotita-xisto }\end{array}$ & $\begin{array}{l}\text { Funil } 2 \\
\text { Granito }\end{array}$ & $\mathrm{U}$ & $\mathrm{p}$ \\
\hline $\mathrm{pH}\left(\mathrm{H}_{2} \mathrm{O}\right)$ & $5,77 \pm 0,36$ & $5,72 \pm 0,14$ & 204,50 & 0,903 \\
\hline $\mathrm{pH}(\mathrm{KCl})$ & $4,59 \pm 0,63$ & $4,62 \pm 0,27$ & 162,50 & 0,310 \\
\hline $\mathrm{C}(\%)$ & $1,74 \pm 0,33$ & $1,80 \pm 0,39$ & 13,50 & 0,46 \\
\hline $\mathrm{N}(\%)$ & $0,20 \pm 0,02$ & $0,24 \pm 0,03$ & 7,00 & 0,06 \\
\hline $\mathrm{P}\left(\mathrm{mg} \cdot \mathrm{dm}^{-3}\right)$ & $1,70 \pm 0,85$ & $1,67 \pm 0,51$ & 195,50 & 0,895 \\
\hline $\mathrm{K}^{1+}\left(\mathrm{mg} \cdot \mathrm{dm}^{-3}\right)$ & $139,54 \pm 42,55$ & $221,85 \pm 49,77$ & 41,00 & $<0,001$ \\
\hline $\mathrm{Fe}^{3+}\left(\mathrm{cmol}_{\mathrm{c}} \cdot \mathrm{dm}^{-3}\right)$ & $2,88 \pm 1,30$ & $3,29 \pm 1,59$ & 164,00 & 0,330 \\
\hline $\mathrm{Mn}^{2+}\left(\mathrm{cmol}_{\mathrm{c}} \cdot \mathrm{dm}^{-3}\right)$ & $8,33 \pm 0,50$ & $8,56 \pm 0,14$ & 151,50 & 0,189 \\
\hline $\mathrm{Ca}^{2+}\left(\mathrm{cmol}_{\mathrm{c}} \cdot \mathrm{dm}^{-3}\right)$ & $6,03 \pm 4,32$ & $6,59 \pm 3,11$ & 166,00 & 0,358 \\
\hline $\mathrm{Mg}^{2+}\left(\mathrm{cmol}_{\mathrm{c}} \cdot \mathrm{dm}^{-3}\right)$ & $0,58 \pm 0,37$ & $0,54 \pm 0,26$ & 210,50 & 0,776 \\
\hline $\mathrm{Al}^{3+}\left(\mathrm{cmol}_{\mathrm{c}} \cdot \mathrm{dm}^{-3}\right)$ & $0,28 \pm 0,31$ & $0,12 \pm 0,07$ & 248,50 & 0,178 \\
\hline Areia grossa $\left(\mathrm{g} \cdot \mathrm{kg}^{-1}\right)$ & $117,60 \pm 74,08$ & $349,15 \pm 38,64$ & 7,00 & $<0,001$ \\
\hline Areia fina $\left(\mathrm{g} \cdot \mathrm{kg}^{-1}\right)$ & $331,15 \pm 66,51$ & $202,30 \pm 27,68$ & 389,50 & $<0,001$ \\
\hline Silte $\left(\mathrm{g} \cdot \mathrm{kg}^{-1}\right)$ & $250,10 \pm 54,89$ & $184,75 \pm 28,91$ & 357,50 & $<0,001$ \\
\hline Argila $\left(\mathrm{g} \cdot \mathrm{kg}^{-1}\right)$ & $296,15 \pm 51,92$ & $264 \pm 21,79$ & 292,00 & 0,013 \\
\hline
\end{tabular}

(Tab. 3). O teor de umidade também divergiu entre as profundidades analisadas nos dois ambientes (ANOVA $F=4,20 ; g l=3 ; p<0,001)$. A umidade foi maior nas camadas mais superficiais do solo $(0-10 \mathrm{~cm})$, diminuindo, gradativamente, conforme o aumento da profundidade. Os valores médios de umidade apresentados pelos solos de Funil 1 e Funil 2 foram muito similares, excetuando-se o mês de setembro, auge da seca, não foi detectada nenhuma variação significativa entre os percentuais de umidade desses solos (Tab. 3).

Distribuição das espécies - As análises de variância conduzidas para as propriedades físicas e químicas do solo mostraram que as variáveis ambientais correlacionadas com a distribuição das espécies nos ambientes estudados (Teste de Monte Carlo, $p<0,05$ ) foram: $\mathrm{P}, \mathrm{Fe}$ e areia grossa em Funil 1; $\mathrm{Fe}, \mathrm{Ca}, \mathrm{Mg}$ e $\mathrm{Al}$ em Funil 2. Os autovalores da CCA para os dois primeiros eixos de ordenação foram baixos nos dois ambientes: 0,17 (eixo 1) e 0,14 (eixo 2) para Funil 1; 0,27 (eixo 1) e 0,14 (eixo 2) para Funil 2. Os dois primeiros eixos juntos explicaram apenas $38,4 \%$ (Funil 1) e 39,6\% (Funil 2) da variância global dos dados, indicando muito ruído ou variância remanescente não explicada. Apesar disso, a significância das relações espécie-ambiente não

Tabela 3. Umidade à base de massa $\left(\mathrm{g} \cdot \mathrm{kg}^{-1}\right)$ obtida para os solos das florestas deciduais de Funil 1 e Funil 2 , vale do rio Araguari, MG, Brasil, ao longo do ano de 2005 em três diferentes profundidades. N = número de amostras; D.P.= desvio-padrão; F = resultado da análise de variância em blocos casualizados; $\mathrm{p}=$ probabilidade da hipótese nula.

\begin{tabular}{|c|c|c|c|c|c|c|c|c|}
\hline & \multirow[b]{2}{*}{$\begin{array}{l}\text { Profundidade } \\
\quad(\mathrm{cm})\end{array}$} & \multirow[b]{2}{*}{$\mathrm{N}$} & \multicolumn{2}{|c|}{ Funil 1} & \multicolumn{2}{|c|}{ Funil 2} & \multirow[b]{2}{*}{$F$} & \multirow[b]{2}{*}{$\mathrm{p}$} \\
\hline & & & $\begin{array}{l}\text { Média } \\
\left(\mathrm{g} . \mathrm{kg}^{-1}\right)\end{array}$ & D.P. & $\begin{array}{l}\text { Média } \\
\left(\mathrm{g} \cdot \mathrm{kg}^{-1}\right)\end{array}$ & D.P. & & \\
\hline Março & $\begin{array}{c}0-10 \\
20-30 \\
40-50\end{array}$ & $\begin{array}{l}10 \\
10 \\
10\end{array}$ & $\begin{array}{l}271,5 \\
196,3 \\
130,4\end{array}$ & $\begin{array}{l}59,7 \\
56,7 \\
57,1\end{array}$ & $\begin{array}{l}229,3 \\
189,6 \\
121,5\end{array}$ & $\begin{array}{l}40,2 \\
38,0 \\
37,9\end{array}$ & 0,296 & 0,589 \\
\hline Junho & $\begin{array}{c}0-10 \\
20-30 \\
40-50\end{array}$ & $\begin{array}{l}10 \\
10 \\
10\end{array}$ & $\begin{array}{r}188,7 \\
113,3 \\
71,5\end{array}$ & $\begin{array}{l}64,3 \\
63,1 \\
63,5\end{array}$ & $\begin{array}{r}209,2 \\
178,5 \\
85,3\end{array}$ & $\begin{array}{l}55,0 \\
53,7 \\
52,8\end{array}$ & 0,851 & 0,360 \\
\hline Setembro & $\begin{array}{c}0-10 \\
20-30 \\
40-50\end{array}$ & $\begin{array}{l}10 \\
10 \\
10\end{array}$ & $\begin{array}{l}76,1 \\
80,2 \\
46,8\end{array}$ & $\begin{array}{l}23,8 \\
25,6 \\
26,9\end{array}$ & $\begin{array}{r}101,1 \\
93,5 \\
76,5\end{array}$ & $\begin{array}{l}19,5 \\
19,1 \\
17,5\end{array}$ & 20,00 & $<0,001$ \\
\hline Dezembro & $\begin{array}{c}0-10 \\
20-30 \\
40-50\end{array}$ & $\begin{array}{l}10 \\
10 \\
10\end{array}$ & $\begin{array}{l}269,4 \\
207,9 \\
152,1\end{array}$ & $\begin{array}{l}54,1 \\
54,5 \\
54,3\end{array}$ & $\begin{array}{l}263,9 \\
241,9 \\
170,9\end{array}$ & $\begin{array}{l}53,5 \\
56,0 \\
56,8\end{array}$ & 0,782 & 0,380 \\
\hline
\end{tabular}


foi prejudicada, pois a CCA produziu altas correlações espécie-ambiente nos dois primeiros eixos: 0,76 (eixo 1) e 0,77 (eixo 2) para Funil 1; 0,86 (eixo 1) e 0,69 (eixo 2) para Funil 2. Quanto à ordenação das espécies pela CCA, ainda em Funil 1, tudo indica que, excetuando-se Lithraea molleoides (C) e Myrcia splendens (D), as demais espécies distribuíram-se, preferencialmente, em solos menos arenosos. Além disso, Myrsine umbellata (A) parece ser mais freqüente em solos onde o teor de $\mathrm{P}$ é maior; Myracrodruon urundeuva (B) distribuiu-se de forma mais uniforme por toda área, respondendo de maneira semelhante às variáveis ambientais consideradas. Quanto a Anandenanthera colubrina (E) e Campomanesia velutina (F), essas espécies foram mais freqüentes em solos com baixos teores de Fe (Fig. 3).

$\mathrm{O} 1^{\circ}$ eixo de ordenação da CCA realizada para Funil 2 revelou a existência de parcelas com propriedades químicas distintas (Fig. 4). O $2^{\circ}$ eixo de ordenação também permitiu verificar uma clara separação das parcelas, só que nesse eixo, a separação ocorreu, primordialmente, em virtude de variações dos teores de $\mathrm{Al}$ no solo (Fig. 4). No tocante à ordenação das espécies pela CCA, ainda em Funil 2, ficou evidente que a espécie Bauhinia ungulata (A) ocorre, preferencialmente, em solos com teores mais elevados de $\mathrm{Fe}$, enquanto Campomanesia velutina (B) parece ter sua distribuição influenciada pelos teores de $\mathrm{Mg}$ e Fe no solo. As leguminosas Acacia polyphylla (E), Anandenanthera

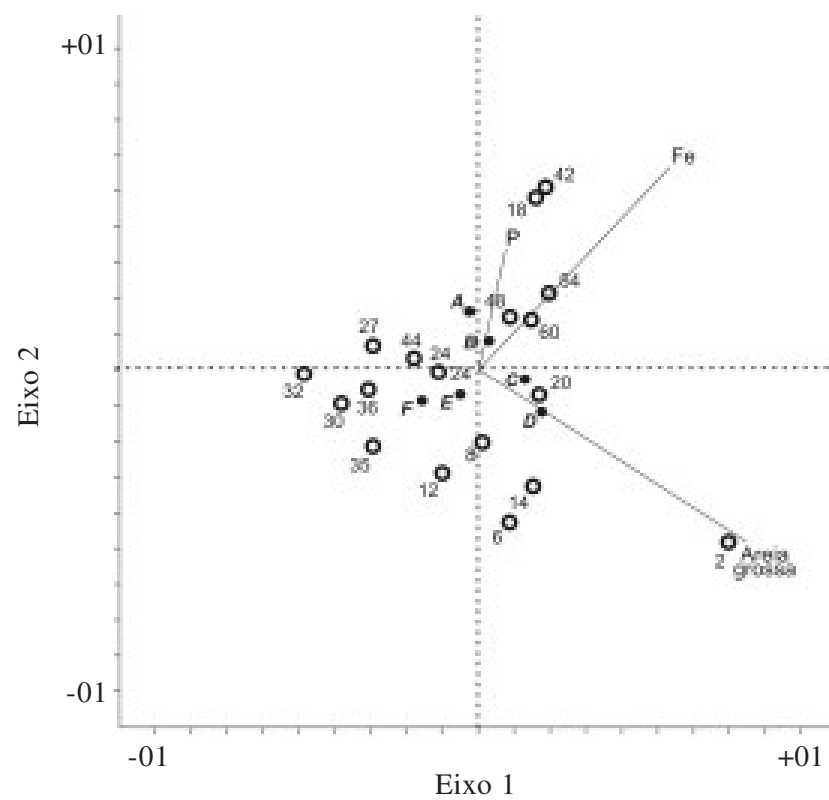

Figura 3. Diagrama de ordenação das parcelas (círculos abertos) e espécies (círculos fechados) obtido para o fragmento de floresta decidual Funil 1, Araguari, MG, Brasil. (A = Myrsine umbellata; $\mathrm{B}=$ Myracrodruon urundeuva $; \mathrm{C}=$ Lithraea molleoides $; \mathrm{D}=$ Myrcia splendens $; \mathrm{E}=$ Anadenanthera colubrina $; \mathrm{F}=$ Campomanesia velutina). colubrina (F) e Piptadenia gonoacantha (G) distribuíram-se, preferencialmente, em solos cujos teores de Al foram mais acentuados. Por outro lado, Myracrodruon urundeuva (C) e Tabebuia roseo-alba (D) responderam de maneira semelhante às variáveis ambientais consideradas, distribuindo-se independentemente por toda a área (Fig. 4).

\section{Discussão}

Diversidade e estrutura da flora - As florestas estacionais deciduais, embora compartilhem espécies vegetais com outras formações, apresentam composição florística peculiar (Pedralli 1997). A composição florística, de forma geral, é influenciada pelas propriedades químicas do solo, pela topografia, por microambientes (como clareiras e áreas em diferentes estádios de sucessão) e, ainda, pela vegetação de áreas adjacentes (Pagano \& Leitão Filho 1987; Rodrigues et al. 1989; Cesar \& Leitão Filho 1990). A flora observada nas florestas deciduais, salvo algumas exceções, é composta por famílias comumente encontradas em florestas úmidas, sendo Fabaceae e Bignoniaceae as famílias mais representativas desse ambiente. Fabaceae é representada, principalmente, por elementos arbóreos, já Bignoniaceae é uma família usualmente dominada por lianas (Gentry 1995). Além de ser uma família característica das florestas decíduas,

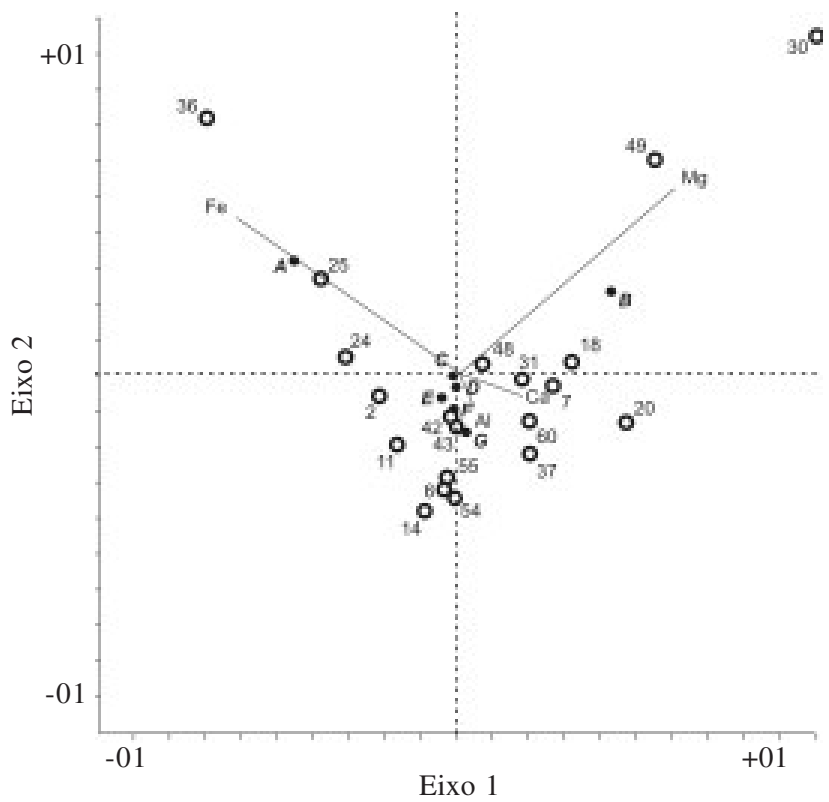

Figura 4. Diagrama de ordenação das parcelas (círculos abertos) e espécies (círculos fechados) obtido para o fragmento de floresta decidual Funil 2, Uberlândia, MG, Brasil. (A = Bauhinia ungulata; $\mathrm{B}=$ Campomanesia velutina $; \mathrm{C}=$ Myracrodruon urundeuva $;$ $\mathrm{D}=$ Tabebuia roseo-alba $; \mathrm{E}=$ Acacia polyphylla $; \mathrm{F}=$ Anadenanthera colubrina; $\mathrm{G}=$ Piptadenia gonoacantha). 
Siqueira, Araújo \& Schiavini: Estrutura do componente arbóreo e características edáficas de dois fragmentos...

a maior representatividade de Fabaceae em Funil 1 e 2 já era esperada, visto ser uma das famílias botânicas mais diversificada, não apenas nas províncias fitogeográficas Atlântica, dos Cerrados e Amazônica, mas também em todas as regiões tropicais com estação seca marcante, o que inclui a Caatinga (ver referências em Cestaro \& Soares 2004). Já a representatividade de Bignoniaceae nas florestas deciduais, todavia, não está associada a maior diversidade dessa família, mas ao fato de outras famílias estarem ausentes ou pobremente representadas nessas formações (Gentry 1995). Esta situação foi observada em Funil 1 e 2 onde Bignoniaceae apareceu com número relativamente pequeno de espécies (cinco em cada área), mas, em contrapartida, a presença abundante de lianas pertencentes a essa família fez com que a mesma se destacasse entre as demais. Excetuando-se Malvaceae, as famílias mais ricas de Funil 1 e 2 estão entre aquelas citadas por Gentry (1995) como típicas de florestas decíduas da América do Sul. A inclusão de Malvaceae entre as famílias mais importantes de Funil 1 e 2 é devido ao sistema de classificação adotado (APGII 2003). Por este sistema de classificação, espécies posicionadas anteriormente em Bombacaceae foram incluídas em Malvaceae, aumentando, consequentemente, a riqueza de espécies da família.

Diferenças significativas de diversidade entre sítios de florestas deciduais podem estar relacionadas à biogeografia ou a características do ambiente (Scariot \& Sevilha 2005). Segundo Felfili et al. (1993), valores de similaridade inferiores a 0,5 são considerados baixos, indicando pequena semelhança entre os ambientes. $\mathrm{O}$ índice de similaridade obtido para Funil 1 e $2(0,53)$ indica que esses ambientes compartilham elementos de sua flora, assemelhando-se quanto à composição de espécies. Variações na composição florística dessas duas áreas podem ser atribuídas, dentre outros fatores, à inserção desses fragmentos em matrizes diferenciadas. Conforme exposto por Costa \& Scariot (2003), a natureza da matriz que cerca os fragmentos e a forma como ela é manejada interfere, grandemente, nas populações vegetais e animais presentes nessas áreas. A presença de cerradão na periferia de Funil 1, por exemplo, pode ter sido responsável pela ocorrência de espécies da família Vochysiaceae (e.g. Qualea grandiflora e Q. multiflora) no interior dessa floresta.

De maneira semelhante à composição de espécies, a estrutura das florestas tropicais varia muito com as condições de solo, água e luz, bem como entre estádios de regeneração (Botrel et al. 2002). A diminuição progressiva da frequiência de indivíduos arbóreos das menores às maiores classes de diâmetro é considerada uma medida de estabilidade (Meyer 1952). Na realidade, entretanto, as espécies de florestas naturais não apresentam tal distribuição, apesar de convergirem para essa condição (Harper 1977). Essa organização espacial é frequentemente observada em florestas que estão em estádios iniciais de regeneração, onde a formação de grandes adensamentos de árvores finas é bastante comum (Parthasarathy 1991). A grande proporção de indivíduos arbóreos com altura intermediária e diâmetro reduzido em Funil 1 e 2 revelam semelhanças estruturais entre essas formações, indicando que ambas as áreas estão se regenerando. Em Funil 1, todavia, o adensamento de árvores finas é mais acentuado, sendo marcante a presença de indivíduos das espécies Myracrodruon urundeuva e Myrsine umbellata, espécies estas classificadas como secundárias iniciais (Ivanauskas et al. 1999).

Ambientes marcados por condições ambientais extremas, como baixa disponibilidade de água e nutrientes ou com excesso de água e nutrientes, tendem a aumentar a dominância ecológica de algumas espécies. Por outro lado, em ambientes com condições intermediárias, a dominância ecológica é baixa, permitindo a coexistência de várias espécies (Ashton 1990). As florestas estacionais deciduais apresentam condições ambientais extremas: solos férteis com baixa retenção hídrica, fatores que acabam selecionando espécies mais aptas a se estabelecerem nesses ambientes (Silva \& Scariot 2003). Essa dominância ecológica apresentada por pequeno número de espécies foi nítida em Funil 1 e 2, podendo ser constatada pela equabilidade obtida para as duas áreas $\left(J^{\prime}=0,66\right)$ e pela dominância expressiva de apenas quatro espécies em cada ambiente. As espécies mais importantes das comunidades vegetais avaliadas neste trabalho coincidem, em parte, com aquelas consideradas por Felfili (2003) como sendo espécies de ligação florística forte entre fragmentos de florestas decíduas no Brasil, sendo elas: aroeira (Myracrodruon urundeuva), monjolo (Acacia polyphylla), angico (Anadenanthera colubrina) e ipê-branco (Tabebuia roseo-alba). Myracrodruon urundeuva e Anadenanthera colubrina são espécies que apresentam ampla distribuição em áreas tropicais, podendo ser encontradas tanto em habitats muito úmidos quanto em locais secos (Prado \& Gibbs 1993). A presença dessas espécies de ligação, que ocorrem tanto na caatinga nordestina quanto nos chacos argentinos, reforça a sugestão de Prado \& Gibbs (1993) sobre essas florestas terem formado no passado um continuum vegetacional.

Solo e distribuição das espécies - Na região dos Cerrados, as florestas deciduais estão distribuídas em um eixo nordeste-sudoeste, ocorrendo sobre afloramentos calcários; sobre depósitos aluviais ricos em nutrientes e sobre solos originários do derrama- 
mento basáltico do sul de Goiás e Triângulo Mineiro (Scariot \& Sevilha 2005). Na região do vale do rio Araguari, as comunidades vegetais de Funil 1 e 2 encontram-se sobre Neossolos Litólicos: solos rasos e pouco evoluídos, apresentando horizonte A assentado diretamente sobre a rocha. Este tipo de solo geralmente ocorre em áreas bastante acidentadas, apresentando elevados teores de minerais primários pouco resistentes ao intemperismo e, algumas vezes, blocos de rocha semi-intemperizada (Reatto et al. 1998). De acordo com os níveis de acidez ativa listados pela CFSEMG (1999), verifica-se que os valores do $\mathrm{pH} \mathrm{em} \mathrm{H}_{2} \mathrm{O}$ obtidos para os solos de Funil 1 e 2 enquadram os mesmos na categoria de solos com acidez moderada ( $\mathrm{pH} 5,0-5,9)$. Estes valores de $\mathrm{pH}$ são toleráveis, não oferecendo prejuízo ao desenvolvimento da comunidade vegetal, desde que os nutrientes essenciais estejam disponíveis (CFSEMG 1999). Solos ácidos, de forma geral,

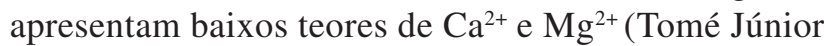
1997), situação esta observada em Funil 1 e Funil 2, onde a disponibilidade dos referidos cátions é menor em relação a outras florestas deciduais do Triângulo Mineiro (Araújo et al. 1997; Souza et al. 2006).

Características físicas do solo, particularmente a umidade e o status de aeração, influenciam diretamente na dinâmica da matéria orgânica, na ciclagem de nutrientes e em sua fertilidade (Ross et al. 1992). O teor de matéria orgânica dos solos fornece importantes informações qualitativas dos mesmos, sendo resultado do balanço entre processos de adição e perda de materiais orgânicos, estando também intimamente relacionado com a umidade nas camadas mais superficiais do solo (Tomé Júnior 1997). Segundo análise estatística conduzida para Funil 1 e 2, não houve diferença significativa entre os teores de matéria orgânica (\%C) e argila desses solos, fato que pode estar relacionado a semelhanças estruturais e florística detectadas entre esses ambientes. Segundo Ross et al. (1992), a umidade do solo e sua fertilidade são as características mais importantes para o estabelecimento e sobrevivência de plântulas, determinando, pois, o conjunto de espécies que poderá se estabelecer em um dado ambiente.

As espécies que compõem uma comunidade vegetal exibem caracteres morfológicos e respostas fisiológicas resultantes da interação solo-planta, interação esta fortemente dependente das condições climáticas e edáficas do ambiente (Cole 1992). As espécies de florestas deciduais são limitadas, primariamente, por água, logo, a topografia e características físicas do solo, fatores que limitam essa disponibilidade, são responsáveis pela maior parte da heterogeneidade espacial e, consequentemente, da distribuição das espécies (Medina 1995; Mooney et al. 1995). Contudo, a influência de propriedades físicas e químicas do solo na determinação da cobertura vegetal ainda é contraditória. De um lado, acredita-se que a vegetação está tão intimamente relacionada ao solo que diferenças pedológicas, inevitavelmente, condicionariam a comunidade de plantas (Brown 1987). Por outro lado, argumenta-se que mudanças na vegetação ocorrem tão rapidamente em comparação a mudanças que se processam no solo que esses dois componentes ambientais (solo e vegetação) não poderiam estar relacionados (Furley 1992). Segundo as análises de ordenação realizadas para Funil 1 e 2 esse impasse permanece, pois os resultados obtidos ainda não são suficientes para explicar a gama de variações observadas nessas comunidades vegetais. A existência de gradientes curtos, ou seja, os baixos valores dos principais eixos da CCA, sugerem que uma ou diversas variáveis não analisadas no presente trabalho estão interferindo na distribuição das espécies. Em outras palavras, não se pode afirmar, no presente caso, que a distribuição das espécies em Funil 1 e 2 esteja condicionada, primariamente, por características químicas e físicas do solo. Variáveis fundamentais, como luz, água e fatores de dispersão das espécies, nem sempre são facilmente perceptíveis ou mensuráveis (Botrel et al. 2002), indicando a necessidade de cautela na interpretação de qualquer resultado de correlações efetuadas entre a distribuição das espécies e variáveis do ambiente físico. Além disso, as espécies de uma comunidade respondem de forma interativa, e não isolada, às condições do ambiente (Botrel et al. 2002), evidenciando a complexidade da relação solo-planta que, para seu correto entendimento, ainda demandará muitos anos de trabalho e pesquisa nesse campo de incipientes descobertas.

\section{Agradecimentos}

Ao Consórcio Capim Branco Energia, pelo apoio financeiro; aos colegas de pós-graduação Victor Hugo de Paula Rodrigues e Ricardo Kilca, pelo companheirismo nas atividades de campo; aos professores Dr. Heraldo Luis Vasconcelos e Dra. Kátia Facure (UFU), pelas orientações nas análises estatísticas; ao Prof. Dr. Gilberto Corrêa Fernandes (UFU), pela identificação e classificação dos solos; ao designer publicitário Disney Torbitoni, pelo auxílio na confecção das figuras.

\section{Referências bibliográficas}

APG II. 2003. An update of the Angiosperm Phylogeny Group classification for the orders and families of flowering plants: APG II. Botanical Journal of the Linnean Society 141: 339-436. 
Allen, S.E. 1974. Chemical analysis of ecological materials. Oxford, Blackwell Scientific Publications.

Araújo, G.M.; Rodrigues, L.A. \& Ivizi, L. 1997. Estrutura fitossociológica e fenologia de espécies lenhosas de Mata Decídua em Uberlândia, MG. Pp. 22-28. In: L.L. Leite \& C.H. Saito (eds.). Contribuição ao conhecimento ecológico do Cerrado. Brasília, Universidade de Brasília.

Ashton, P.S. 1990. Species richness in tropical forests. Pp. 239-251. In: L.B. Holm-Nielsen; I.C. Nielsen \& H. Balslev. (eds.). Tropical forests - botanical dynamics, speciation and diversity. London, Academic Press.

Baruqui, F.M. \& Motta, P.E.F. 1983. Interpretação de um trecho do mapa de solos do Triângulo Mineiro. Informe Agropecuário 9: 45-63.

Botrel, R.T.; Oliveira Filho, A.T.; Rodrigues, L.A. \& Curi, N. 2002. Influência do solo e topografia sobre as variações da composição florística e estrutura da comunidade arbóreaarbustiva de uma floresta estacional semidecidual em Ingaí, MG. Revista Brasileira de Botânica 25: 195-213.

Brown, K.S. 1987. Soils and vegetation. Pp. 19-45. In: T.C. Whitmore \& G.T. Prance (eds.). Biogeography and Quartenary History in Tropical America. Oxford, Clarendon Press.

Causton, D.R. 1988. An introduction to vegetation analysis, principles, practice and interpretation. London, Unwin Hyman.

Cesar, O. \& Leitão Filho, H.F. 1990. Estudo florístico quantitativo de mata mesófila semidecídua na Fazenda Barreiro Rico, Município de Anhembi, São Paulo. Revista Brasileira de Biologia 50: 133-147.

Cestaro, L.A. \& Soares, J.J. 2004. Variações florística e estrutural e relações fitogeográficas de um fragmento de floresta decídua no Rio Grande do Norte, Brasil. Acta Botanica Brasilica 18: 203-218.

CFSEMG - Comissão de Fertilidade do Solo do Estado de Minas Gerais. 1999. Recomendações para uso de corretivos e fertilizantes em Minas Gerais. $5^{a}$ aproximação. Viçosa, Ed. Viçosa.

Cole, M.M. 1992. Influence of physical factors on the nature and dynamics of forest-savanna boundaries. Pp. 63-76. In: J.P. Furley \& J.A. Ratter (eds.). Nature and dynamics of forestsavanna boundaries. London, Champman \& Hall.

Costa, R.B. \& Scariot, A. 2003. A fragmentação florestal e os recursos genéticos. In: R.B. Costa (org.). Fragmentação florestal e alternativas de desenvolvimento rural na região centro-oeste. Campo Grande, Universidade Católica Dom Bosco.

EMBRAPA. 1982. Serviço Nacional de Levantamento e Conservação de Solo. Levantamento de média intensidade e avaliação da aptidão agrícola das terras da área do Triângulo Mineiro. Rio de Janeiro, EMBRAPA- SNLCS: EPAMIG-DRNR.

EMBRAPA. 1997. Manual de métodos de análise do solo. $2^{\mathrm{a}}$ ed. Rio de Janeiro, Ministério da agricultura e do abastecimento.

EMBRAPA. 1999. Sistema brasileiro de classificação de solos. Rio de Janeiro, Embrapa Produção de Informação.

Felfili, J.M. 2003. Fragmentos de florestas estacionais do Brasil Central: diagnóstico e proposta de corredores ecológicos. Pp. 139-160. In: R.B. Costa. (org.). Fragmentação Florestal e alternativas de desenvolvimento rural na região CentroOeste. Campo Grande, Universidade Católica Dom Bosco.

Felfili, J.M.; Silva Júnior, M.C.; Rezende, A.V.; Machado, J.W.B.; Walter, B.M.T.; Silva, P.E.N. \& Hay, J.D. 1993. Análise comparativa da florística e fitossociologia da vegetação arbórea do cerrado sensu stricto na Chapada Pratinha, DF-Brasil. Acta Botanica Brasilica 6: 27-47.
Furley, P.A. 1992. Edaphic changes at the forest-savanna boundary with particular reference to the neotropics. Pp. 91-118. In: J.P. Furley \& J.A. Ratter (eds.). Nature and dynamics of forest-savanna boundaries. London, Champman \& Hall.

Gentry, A.H. 1995. Diversity and floristic composition of neotropical dry forest. Pp. 146-194. In: S.H. Bullock; H.A. Mooney \& E. Medina. (eds.). Seasonally dry tropical forests. New York, Cambridge University Press.

Harper, J.L. 1977. Population biology of plants. London, Academic Press.

Ivanauskas, N.M.; Rodrigues, R.R. \& Nave, A.G. 1999. Fitossociologia de um remanescente de floresta estacional semidecidual em Itatinga-SP, para fins de restauração de áreas degradadas. Scientia Florestalis 56: 83-99.

Medina, E. 1995. Diversity of life forms of higher plants in neotropical dry forests. Pp. 221-242. In: S.H. Bullock; H.A. Mooney \& E. Medina (eds.). Seasonally dry tropical forests. New York, Cambridge University Press.

Meyer, H.A. 1952. Structure, growth, and drain balanced unevenaged forests. Journal of Forest 50: 85-92.

Mooney, H.A.; Bullock, S.H. \& Medina, E. 1995. Introduction. Pp.1-8. In: S.H. Bullock; H.A. Mooney \& E. Medina (eds.). Seasonally dry tropical forests. New York, Cambridge University Press.

Mueller-Dombois, D. \& Ellenberg, H. 1974. Aims and methods of vegetation ecology. New York, Wiley \& Sons.

Nascimento, A.R.T.; Felfili, J.M. \& Meirelles, E.M. 2004. Florística e estrutura da comunidade arbórea de um remanescente de Floresta Estacional Decidual de encosta, Monte Alegre, GO, Brasil. Acta Botanica Brasilica 18: 659-669.

Nishyiama, L. 1989. Geologia do município de Uberlândia e áreas adjacentes. Sociedade e Natureza 1: 9-16.

Oliveira Filho, A.T.; Curi, N.; Vilela, E.A. \& Carvalho, D.A. 1998. Effects of canopy gaps, topography and soils on the distribution of woody species in a central Brazilian deciduous dry forest. Biotropica 30: 362-375.

Oliveira Filho, A.T.; Curi, N.; Vilela, E.A. \& Carvalho, D.A. 2001. Variation in tree community composition and structure with changes in soil properties within a fragment of semideciduous forest in south-eastern Brazil. Edinburgh Journal of Botany 58: $139-158$.

Pagano, S.N. \& Leitão Filho, H.F. 1987. Composição florística do estrato arbóreo de mata mesófila semidecídua no município de Rio Claro (Estado de São Paulo). Revista Brasileira de Botânica 10: 37-47.

Parthasarathy, N. 1991. Tree diversity and distribution in undisturbed and human-impacted sites of tropical wet evergreen forest in southern Western Ghats, India. Biodiversity and Conservation 8: 1365-1381.

Pedralli, G. 1997. Florestas secas sobre afloramentos calcários em Minas Gerais: florística e fisionomia. Bios 5: 81-88.

Prado, D. \& Gibbs, P. 1993. Patterns of species distributions in the dry seasonal forests of South America. Annals of the Missouri Botanical Garden 80: 902-927.

Reatto, A.; Correia, J.R. \& Spera, S.T. 1998. Solos do Bioma Cerrado. Pp. 47-83. In: S.M. Sano \& S.P. Almeida (eds.). Cerrado: ambiente e flora. Planaltina, EMBRAPA-CPCA.

Ricklefs, R.E. 2003. A economia da natureza. 5a ed. Rio de Janeiro, Ed. Guanabara Koogan S.A.

Rodrigues, L.A. \& Araújo, G.M. 1997. Levantamento florístico de uma mata decídua em Uberlândia, Minas Gerais, Brasil. Acta Botanica Brasilica 11: 229-236. 
Rodrigues, R.R.; Morellato, L.P.C.; Joly, C.A. \& Leitão Filho, H.F. 1989. Estudo florístico e fitossociológico em um gradiente altitudinal de mata estacional mesófila semidecídua, na Serra do Japi, Jundiaí, SP. Revista Brasileira de Botânica 12: 71-84.

Rosa, R.; Lima, S.C. \& Assunção, W.L. 1991. Abordagem preliminar das condições climáticas de Uberlândia (MG). Sociedade e Natureza 3: 91-108.

Ross, S.M.; Luizão, F.J. \& Luizão, R.C.C. 1992. Soil condition and soil biology in different habitats across a forest-savanna boundary on Maracá Island, Roraima, Brazil. Pp. 145-170. In: J.P. Furley \& J.A. Ratter (eds.). Nature and dynamics of forest-savanna boundaries. London, Champman \& Hall.

Scariot, A. \& Sevilha, A.C. 2005. Biodiversidade, estrutura e conservação de florestas estacionais deciduais no Cerrado. Pp. 121-139. In: A. Scariot; J.C. Sousa-Silva \& J.M. Felfili (orgs.). Cerrado: ecologia, biodiversidade e conservação. Brasília, Ministério do Meio Ambiente.

Shepherd, G.J. 1995. FITOPAC I: manual do usuário. Campinas, Departamento de Botânica, Universidade Estadual de Campinas.

Silva, L.A. \& Scariot, A. 2003. Composição florística e estrutura da comunidade arbórea em uma floresta estacional decidual em afloramento calcáreo (Fazenda São José, São Domingos, GO, Bacia do Rio Paraná). Acta Botanica Brasilica 17: 305-313.
SIMGE- Sistema de informações meteorológicas do Estado de Minas Gerais. 2006. Disponível em: <www.simge.mg.gov.br> (Acessado em: 10/06/2006).

Souza, V.C. \& Lorenzi, H. 2005. Botânica Sistemática- Guia ilustrado para identificação das famílias de angiospermas da flora brasileira, baseado em APG II. Nova Odessa, São Paulo, Ed. Plantarum.

Souza, J.P.; Araújo, G.M. \& Haridasan, M. 2006. Influence of soil fertility on the distribution of tree species in a deciduous forest in the Triângulo Mineiro region of Brazil. Plant Ecology 191: 253-263.

Ter Braak, C.J.F. 1987. The analysis of vegetation-environment relationships by canonical correspondence analysis. Vegetatio 69: 69-77.

Ter Braak, C.J.F. 1988. CANOCO- A FORTRAN program for canonical community ordination by correspondence analysis principal, components analysis and redundancy analysis. Version 2.1. Wageningen, Institute of Applied Computer Science.

Tomé Júnior, J.B. 1997. Manual para interpretação e análise do solo. Guaíba, Ed. Agropecuária.

Veloso, H.P.; Rangel Filho, A.L.R. \& Lima, J.C.A. 1991. Classificação da vegetação brasileira adaptada a um sistema universal. Rio de Janeiro, Instituto Brasileiro de Geografia e Estatística. 